\title{
Onde os fracos não têm vez: discursos sobre anabolizantes, corpo e masculinidades em uma revista especializada
}

I Fatima Regina Cecchetto, ${ }^{2}$ Patricia Silveira de Farias,
${ }^{3}$ Paulo Rodrigo Pedroso da Silva, ${ }^{4}$ Juliana Silva Corrêa I

Resumo: O objetivo deste estudo é analisar as matérias sobre esteróides anabolizantes androgênicos (EAA) e doping, publicadas em uma revista especializada em artes marciais, a Tatame, entre os anos 1996 e 2010. Utilizou-se metodologia qualitativa, a partir do referencial fornecido pelas Ciências Sociais e suas interfaces com o campo da Saúde Coletiva. A análise e discussão dos discursos acerca do uso de EAA e doping foram organizados em quatro etapas: na primeira, ocorreu uma leitura abrangente do material jornalístico; na segunda etapa, foram examinadas as matérias, focalizando os títulos, subtítulos e conteúdos. Na terceira, verificou-se o meio circundante dos boxes, capas, contracapas e espaços publicitários da revista. A quarta etapa privilegiou a perspectiva dos lutadores sobre a utilização de EAA e/ ou doping, veiculadas tanto nas matérias em que estes usos são o foco central, quanto em reportagens em que estes não são a temática principal. Os resultados indicam um descompasso entre os conteúdos veiculados na imprensa, que, de um lado, condenam o uso de EAA e doping, e de outro, divulgam uma série de estímulos para o desenvolvimento da musculosidade. Desta forma, os conteúdos acabam por corroborar a ideia de uma estreita associação entre musculosidade e um tipo de masculinidade tradicional ancorado na positivação da força e na invencibilidade.

> Palavras-chave: doping; esteróides anabolizantes; ethos guerreiro; masculinidade; meios de comunicação.

\author{
1 Doutora em Saúde Coletiva \\ pela Universidade do Estado \\ do Rio de Janeiro (UERJ); \\ pesquisadora do Laboratório \\ de Educação em Ambiente e \\ Saúde da Fiocruz e professora \\ da Escola Nacional de Saúde \\ Pública (ENSP). Endereço \\ eletrônico: facecchetto@gmail. \\ com \\ 2 Doutora em Antropologia \\ Cultural pela Universidade \\ Federal do Rio de Janeiro \\ (UFRJ); professora adjunta \\ do Departamento de Política \\ Social da ESS-UFRJ. Endereço \\ eletrônico: trapfarias@gmail. \\ com \\ ${ }^{3}$ Mestre em Ciências \\ Médicas-Endocrinologia pela \\ Universidade Federal do Rio \\ Grande do Sul; pesquisador \\ do Programa de Capacitação \\ Profissional em Serviço do \\ Laboratório de Educação em \\ Ambiente e Saúde no Instituto \\ Oswaldo Cruz. Endereço \\ eletrônico: rodrigomettrica@ \\ gmail.com \\ ${ }^{4}$ Mestranda do Programa \\ de Pós-Graduação em \\ Saúde Pública da ENSP- \\ Fiocruz. Endereço eletrônico:
} correajugeo@gmail.com
Recebido em: 31/03/2011. Aprovado em: 25/04/2012. 
Não chega a ser novidade de que o corpo musculoso é visto como um ícone da masculinidade. Ser maior, mais forte, ou usar a força para resolver conflitos e vencer os outros são características frequentemente valorizadas, ao passo que ser menor, ter uma compleição física pequena, ou fazer uso da palavra no lugar de músculos não são em geral atributos masculinos enaltecidos.

A imagem socialmente valorizada de um homem másculo é discutida nos estudos pioneiros realizados por Klein (1993) e Courtine (1995), que assinalam o desenvolvimento de uma cultura masculina associada à musculosidade exacerbada no cenário atual. Constata-se ainda a presença deste ideal entre alguns praticantes de musculação (SABINO, 2006; IRIAT, 2009) e de artes marciais (WACQUANT, 2002), e é a tônica da motivação dos chamados pitboys, personagem intimidador cujo símbolo máximo é a ostentação de emblemas másculos quase sempre construídos a base de substâncias anabolizantes (CECCHETTO, 2004; 2009).

Com efeito, estaríamos testemunhando o recrudescimento de um novo modelo de corpo masculino: a hipermasculinidade, cuja característica principal é a supervalorização de "marcas" masculinas, sejam elas psicológicas ou físicas. Neste registro, a musculosidade e o que isso conota - poder, dominação e virilidade -, são equacionados ao masculino, opondo-se à fraqueza, atributo associado ao "feminino", reiterando uma divisão rígida dos papéis de gênero (KLEIN, 1993 , p. 5). Alguns homens, como que respondendo a esta realidade, buscam a transformação muscular por meio de esteróides anabolizantes, sacrificando o corpo a ponto de colocar em risco a saúde para atingir as medidas desejadas (POPE et al., 1999). ${ }^{1}$ Nessa direção, Le Breton (2003) já chamara a atenção para uma tendência contemporânea da "produção farmacológica de si”, que assume o corpo como algo "em construção", passível de sofrer modificações a partir do desejo individual. Para estas mudanças, o paradigma é o uso de produtos químicos e farmacológicos.

Os danos provocados pelo uso indevido dessas substâncias têm sido destacados em artigos biomédicos, que se dedicam a examinar o perigo dos anabolizantes, denominados como "bombas" no circuito esportivo. Nessas visões, o consumo dessas substâncias é recriminado, tanto por conta dos riscos à saúde quanto por contrariar as regras esportivas, caracterizando doping (SILVA et al., 2002). Mais 
grave ainda é o uso de "produtos inadequados" para o organismo humano, que podem ser letais. ${ }^{2}$

A despeito desse enfoque, as representações simbólicas da masculinidade no contexto do fitness e do culturismo cada vez mais tomam por base um corpo hipermusculoso como ideal de virilidade e saúde (IRIAT, 2002; SABINO, 2006). Esse padrão de corpo virilizado é sustentado por uma indústria, um mercado e um conjunto de práticas de massas, incluindo o universo publicitário. Cotidianamente, revistas, filmes e outras mídias divulgam imagens de homens, crescentemente mais musculosos, excedendo os limites reais das medidas humanas (POPE et al,. idem).

A imprensa como um lócus de operação e criação de consensos é discutida por Bourdieu (2004), cujas colocações sinalizam o papel dos órgãos especializados em potencializar esses movimentos, dialogando diretamente com os consumidores. A partir daí, tais veículos, com muito maior força do que a imprensa em geral, mas sempre em diálogo com ela, se transformam em latentes prescritores de atitudes, crenças e práticas entre seus leitores (ver as análises de FARIAS 1997 e 2003). Assim, o objetivo aqui é verificar como a musculosidade, enquanto símbolo da masculinidade se manifesta em uma revista que integra o circuito de artes marciais: a Tatame. ${ }^{3}$

Uma das principais publicações desse gênero no país, ela é basicamente consumida por indivíduos do sexo masculino. A revista exprime o modus operandi do lutador que remete a ideias de superioridade, coragem e valentia, simbologia que perpassa o universo das artes marciais. Algumas modalidades exigem mais resistência; outras, força muscular. Há ainda aquelas cuja técnica é a característica mais central. Todas, no entanto, demandam a constituição e manutenção de um ethos guerreiro (ELIAS, 1993), ou seja, um conjunto de disposições físicas e morais direcionadas para o combate (frequentemente violento), visando derrotar o oponente. Tal configuração da masculinidade guerreira se faz realidade não apenas nas atitudes de lutadores, mas também nas matérias jornalísticas que disseminam esses valores.

Nesta direção, encaramos a circulação deste meio impresso específico para este público como um território masculino, cuja atmosfera é atravessada pela ideia de masculinidade hegemônica (MESSNER, 2001), tornando-se assim um viés particularmente fértil para o estudo da construção social das masculinidades. 
Diga-se ainda que a quase total ausência de figuras femininas, seja nos textos ou em imagens, igualmente reforça o caráter androcêntrico da Tatame.

\section{Metodologia}

A pesquisa foi realizada em quatro etapas: na primeira, foi feita uma leitura abrangente do total de 180 revistas publicadas entre os anos de 1996 e 2010 . Na segunda, foram examinadas as matérias que continham as palavras "doping" e "esteróides anabolizantes androgênicos", seus títulos, os subtítulos e conteúdos. Foram também observados boxes que destacam determinado assunto constante em uma página. Na terceira etapa, deu-se destaque para a publicidade de suplementos nutricionais, encontradas nos exemplares selecionados. Numa quarta etapa, analisou-se a perspectiva dos lutadores sobre EAA e doping, tanto nas matérias analisadas quanto no meio circundante da revista.

Como referencial teórico, foi utilizada a abordagem da antropologia cultural, que privilegia a análise dos significados simbólicos da ação social (GEERTZ, 1989). Desta perspectiva, os pontos de vista, concepçóes e expressões do grupo pesquisado podem ser interpretados como textos, conectando-os com a estrutura social mais ampla.

O material foi sistematizado tendo por base a análise temática, uma metodologia adotada no campo da Saúde Coletiva por Minayo (1993), a partir do trabalho icônico de Laurence Bardin dos anos 1970, centrado na análise de conteúdo. Será esse procedimento que utilizaremos a seguir, buscando atingir os significados no que está escrito, mapeado ou simbolicamente explicitado nos conteúdos manifestos e/ou latentes nos textos jornalísticos selecionados.

\section{Interpretando a Tatame}

A revista Tatame aborda as diversas modalidades de artes marciais, com destaque para jiu-jitsu, judô, boxe, muay thai e MMA (mixed martial arts). As matérias se relacionam com o circuito das lutas, apresentando os campeonatos realizados, o cotidiano dos lutadores e entrevistas com os principais campeões dos torneios. Destacam-se conteúdos direcionados à preparação física, abordando temas como nutrição e dietas especializadas para perda de peso, assim como os treinos e rotinas específicas que promovam o aumento de massa muscular. 
Na primeira fase, o ponto que mais chamou atenção foi a escassez de matérias sobre os EAA e doping publicadas em 15 anos: apenas cinco tratavam deste assunto. Destas, quatro faziam parte de um informe publicitário patrocinado por uma empresa de suplementos.

No contexto das academias, o consumo de tais substâncias tem alta prevalência (SILVA et al., 2007). Embora normalmente ocultada, a prática de doping por anabolizantes mantêm estreita relação com as formas musculares exacerbadas da maioria dos praticantes de artes marciais e culturistas (SILVA et al., 2002). Pode-se supor que o silêncio em relação ao assunto estaria expressando o estigma que tais práticas carregam, seguindo o mesmo padrão proibicionista que abrange o uso de drogas ilícitas em geral. Embora fuja ao escopo deste artigo abordar a complexa questão do uso de drogas (lícitas ou ilícitas), a ênfase no proibicionismo é criticada por pesquisadores da saúde publica que discutem os dilemas para a elaboração de uma política nacional de drogas equilibrada que envolva a redução de danos (DOMINGUEZ, 2011).

\section{No corpo da Tatame: os discursos sobre os anabolizantes}

Vimos, em primeiro lugar, os títulos e/ou subtítulos das matérias, pois, conforme indica Ogilvy (apud BELELI, 2007), “o título é mais da metade de uma propaganda impressa". Os títulos "Substâncias ergogênicas e doping" (1998) e "O hormônio do crescimento GH, o anabolizante da moda” (1998) não propõem uma mensagem propriamente condenatória; porém pode ser dito que o enunciado sobre o hormônio de crescimento humano (HGH) sugere que a utilização de agentes hormonais integra um estilo de vida moderno, igualando saúde à moda.

Já os títulos "Anabolizantes: a sua saúde em perigo" (1999) e "Doping: você sabe o que está tomando?” (2000) alertam para os danos provocados por tais substâncias. Tais enunciados dialogam com os leitores como se estes fossem consumidores dessas substâncias. Essa estratégia discursiva sugere um movimento de aproximação com o possível usuário. No mesmo eixo condenatório se expressa a matéria "No flagra" (2010), cujo título define a situação constrangedora de quem foi pego nos exames de doping.

Como pode ser notado, se os dois primeiros títulos não traziam indicativos claros de reprovação ao uso de doping, nos últimos observam-se mudanças que culminam com a reportagem mencionada, cujo tom é uma forma de censura. 
Pode se sugerir que a revista em seus últimos fascículos tenha acompanhado o incremento do doping no circuito esportivo nas últimas duas décadas (KAISER et al., 2007). Alguns dos dilemas do doping são discutidos neste trabalho, focalizando inclusive a perspectiva da redução de danos, ainda pouco abordada na literatura.

Em relação ao corpo das matérias, verificamos que os textos de "O Hormônio do Crescimento GH, o Anabolizante da Moda" (1998) e "Substâncias ergogênicas e doping" (1998) fazem parte de uma seção da revista denominada "Saúde e Alimentação", patrocinada por uma empresa de suplementos. São matérias assinadas pela mesma autora, uma profissional da área da nutrição.

Em apenas uma página, a matéria sobre o HGH descreve as aplicações deste hormônio em diferentes âmbitos: estético, médico e esportivo. Nessa linha, adverte-se o leitor sobre os riscos do consumo do mencionado produto: "É importante que saibamos um pouco mais sobre seus efeitos [HGH] no organismo e os possíveis riscos à saúde associados a altas doses, administradas por longos períodos, antes de pensarmos em começar a utilizá-lo" (n.35, p.46, 1998).

O trecho acima indica o provável reconhecimento da utilização de HGH por quem almeja aumentar o desempenho físico e o aprimoramento estético. A matéria traz ainda informações sobre a maneira como o uso de HGH é percebido no contexto olímpico, apresentando nas entrelinhas o conceito de doping: "Além do uso de GH trazer riscos á saúde, seu uso é considerado ilegal e antiético pelo COI (Comitê Olímpico Internacional), uma vez que o alto rendimento será atingido artificialmente" (ibidem). Na sequência, são indicadas as dificuldades que o COI enfrenta para a detecção do HGH no doping: "o grande problema para o Comitê é que o GH ainda não aparece através dos testes para a detecção de drogas".

Destacamos aqui a intenção da reportagem em caracterizar a dimensão da não detecção como "o grande problema". Paradoxalmente, ao fazer esta colocação, a matéria pode estimular o consumo de HGH como prática de doping intencional.

A matéria "Substâncias ergogênicas e doping" traz inicialmente uma definição para substâncias ergogênicas e suas aplicações no campo esportivo. Nessa linha, os ergogênicos seriam como que "artifícios que visam a melhora da performance". Além disso, há uma classificação dos ergogênicos como "categorias de ajuda", identificando os tipos: nutricional, farmacológica, fisiológica, psicológica, bioquímica e mecânica. A discussão gira em torno da distinção entre os ergogênicos nutricionais e ergogênicos farmacológicos. 
Como exemplos de ergogênicos nutricionais são citadas as bebidas energéticas, os repositores hidroeletrolíticos, as vitaminas antioxidantes, os aminoácidos de cadeia ramificada, entre outros. Dentre os farmacológicos, foi mencionada a anfetamina, definida como substância que mimetiza os efeitos do hormônio epinefrina, secretado naturalmente pelo corpo durante o exercício. A matéria parece dar ênfase aos possíveis benefícios deste recurso, lembrando que sua administração pode "levar ao sucesso no esporte", por conta das alterações promovidas nos processos metabólicos. O artigo termina lembrando que, "apesar de existirem algumas drogas que são ergogênicos eficazes", seu uso pode aumentar o risco de vida e da punição por doping, como é apresentado no trecho a seguir: "lembre-se: antes de começar a utilizar qualquer substância ergogênica, certifique-se que a mesma é saudável e que não lhe trará nenhum problema de saúde, nem fará com que você seja eliminado de uma competição importante por doping" (n. 36, p46, 1998).

Nas duas matérias acima mencionadas, encontramos caricaturas do doping. A primeira mostra a imagem de um homem musculoso, em traje de luta, com sorriso e expressão infantis, insinuando uma relação de afeto com a "sua" seringa e a possibilidade de dependência química e psicológica do usuário de anabolizantes (figura 1). Na segunda, vemos dois atletas em combate (figura 2). Nesta imagem, o cartunista procura transmitir também os efeitos do doping tanto no corpo como na mente do usuário, aludindo a uma competição desleal. O movimento de braços, de pernas e a expressão artificial na face deste atleta, pressupõem a utilização de estimulantes para vencer a luta.

Figura 1 - Caricaturas do Doping (I)

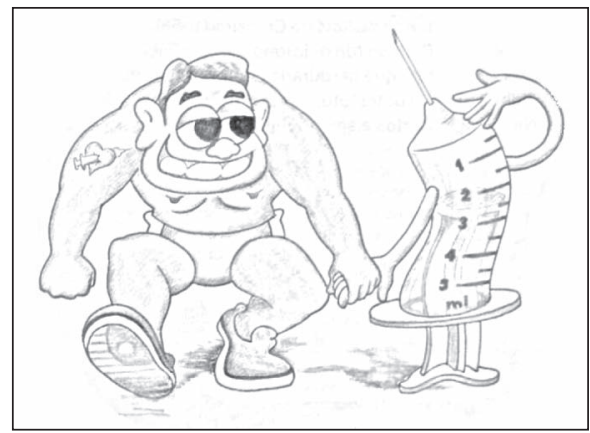

Fonte: Hormônio de Crescimento GH= O Anabolizante da Moda. Ano 4, n.35, p.46
Figura 2 -Caricaturas do Doping (II)

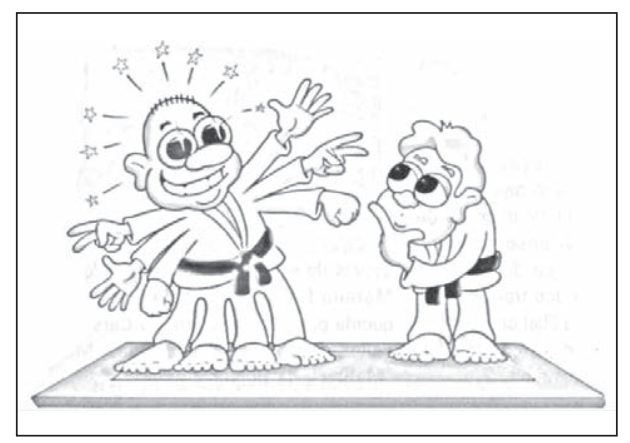

Fonte: Substâncias Ergogênicas e Doping. Ano 4, n.36, s/n. 
O conteúdo das matérias "Anabolizantes: a sua saúde em perigo" (1999) e "Doping: você sabe o que está tomando?" (2000) conjuga informações a respeito do consumo de anabolizantes e as sanções relativas ao doping, não apenas descrevendo as substâncias, mas assinalando a possibilidade inclusive da morte de atletas.

O objetivo da primeira é conceituar uma substância anabólica: "toda e qualquer substância capaz de promover reações de síntese ou processos de reconstrução do tecido muscular". O texto argumenta sobre a diferença entre as substâncias anabólicas consideradas "naturais" (não hormonais) e "hormonais". A testosterona, o DHEA (dehidroepiadrosterona) e a progesterona foram citados como exemplos de substâncias anabólicas hormonais. Como "natural", a reportagem menciona a atividade anabólica proporcionada pela banana e também pelo sono:

[...] os nutrientes liberados [da banana] serão absorvidos por uma infinidade de células, contribuindo para manter um equilíbrio orgânico. O sono após um período de treinamento físico funciona também como um agente anabólico, pois estará ajudando o organismo na sua recuperação (n.48, p.34, 1999).

Nessa linha, estabelece uma clivagem entre os suplementos alimentares e os esteróides anabolizantes, afirmando que os primeiros:

[...] nada mais são do que alimentos ricos em determinados nutrientes, capazes, dependendo de sua composição, de melhorar a performance, a composição corporal, prevenir lesões e melhorar o tempo de recuperação de um atleta. Podem funcionar como substâncias anabolizantes, mas não guardam nenhuma relação com os produtos à base de hormônio (Ibidem).

Permanece certa confusão na passagem de conceitos e conteúdos aos leitores, expondo a ideia de que o suplemento éum anabólico natural e seguro, como a banana e o sono, com benefícios (ex.: performance, composição corporal, recuperação) e sem os riscos dos anabolizantes sintéticos. Posteriormente, se contradiz ao alertar para a possibilidade de existirem alguns esteróides "disfarçados" de suplementos alimentares. Há, no entanto, uma imprecisão do que seja este disfarce ${ }^{4}$. Nessa linha, Pereira et al. (2008, p. 267) alertam para as controvérsias no meio científico sobre seus possíveis efeitos, riscos e benefícios da suplementação com múltiplos nutrientes, já que suas funções não são bem esclarecidas.

A aquisição ilegal dos esteróides nas farmácias se faz presente neste texto. Os principais esteróides anabolizantes mencionados são o Winstrol, o Primobolan, o Anavar e o Hormônio do Crescimento (HGH). Observa-se o apoio a medidas 
punitivas em relação à comercialização de substâncias anabolizantes no chamado "mercado negro de esteróides", do qual também faz parte a internet. As ações sempre citadas são: a fiscalização e punição de médicos e professores; a cassação dos registros de profissionais que não seguirem as normas e, por fim, a interdição e multa de academias e estabelecimentos irregulares.

Os balconistas das lojas de suplementos e os usuários de anabolizantes são apontados como incentivadores, na medida em que tais substâncias específicas são comercializadas por alguns deles. Como foi descrito, o tom desta reportagem é alarmista, apontando visivelmente para uma intenção em explicitar o risco, tornálo central na matéria. Nessa direção é abordado o caso de uma mulher culturista de 33 anos que morreu ao final da década de 90 devido a complicaçóes decorrentes da ingestão de esteróides anabolizantes. A matéria reforça a condenação do uso estético de EAA, reproduzindo fotos ampliadas de um corpo masculino hipertrofiado em posição de culturismo, junto com ampolas e seringas (figura 3).

Figura 3 - As consequências do Doping (I)

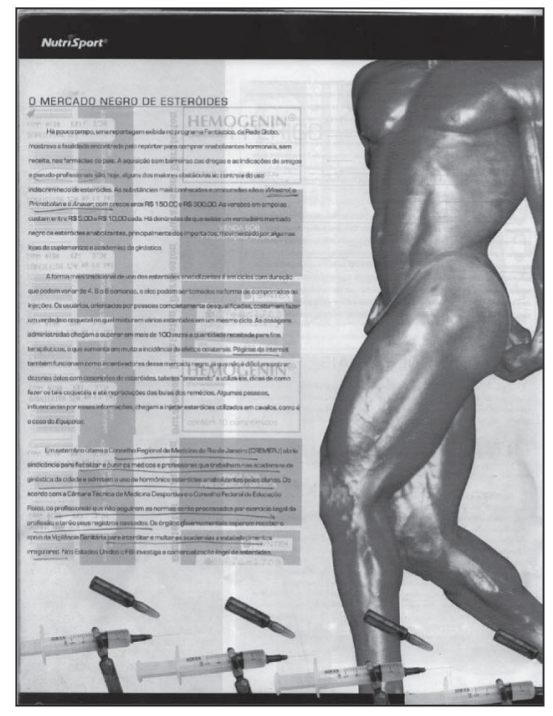

Fonte: Anabolizantes: a sua saúde em perigo. Ano 5, n.48, p.34-36.

Já na matéria "Doping: você sabe o que está tomando?" o maior dos vilóes apontados é o Potenay, substância que foi a provável causa da morte súbita de um atleta de 23 anos em campeonato mundial de jiu-jitsu realizado no Brasil em 

educação física, ao que tudo indica consultor da revista, já que em duas das cinco matérias analisadas é convocado a fornecer um parecer:

O Potenay é um complexo B neuroestimulante. É uma espécie de estimulante para fazer o cavalo correr mais. Só que é para cavalo! Considerando que a dosagem para um cavalo de 500 quilos seja bem maior do que a indicada para um homem de 70 quilos, já se tem um bom motivo para o choque que matou o rapaz (n.56, s/p, 1998).

Ele recomenda que o usuário inicie uma terapia nos moldes do tratamento usual para dependência química, isto é, com a diminuição gradativa do consumo, feita sob orientação médica e de maneira "lícita":

[os anabolizantes] todos têm efeitos colaterais sérios, mas que só aparecem com o uso prolongado. Quem estiver fazendo uso de estimulantes ou anabolizantes, não precisa se apavorar. Procure um médico, abra o jogo e inicie um programa para deixar de tomar as substâncias. Existem várias maneiras lícitas e não prejudiciais à saúde de se obter ganho de massa muscular, força e resistência, sem a necessidade de recorrer a drogas perigosas (Ibidem).

O que fica deste relato é a indefinição do que sejam drogas perigosas, assim como sobre as formas de ingerir substâncias que promovem o incremento de musculosidade, força e resistência que não sejam ilegais.

\section{Figura 4 - As consequências do Doping (II)}

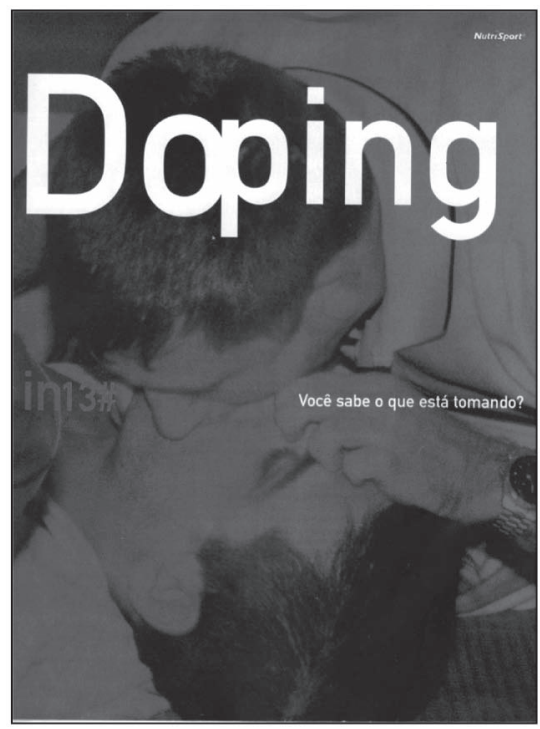

Fonte: Doping: Você sabe o que está tomando?

Ano 6, n. 56, s/n. 
Tal destaque reafirma o reconhecimento, em parte, do chamado uso nãomédico ou estético dos EAA (HANDELSMAN, 2006), configurando uma preocupação em legitimar a vertente terapêutica: "Só quem pode receitar qualquer substância, incluindo os suplementos mais simples, é um médico ou nutricionista. $\mathrm{O}$ professor de educação física ou de artes marciais que for pego desempenhando este papel será punido" (Ibidem).

Há o reforço da autoridade do médico e do nutricionista quando se trata de prescrever essas substâncias ergogênicas, ainda que os nutricionistas só possuam de fato competência para receitar suplementos. Pode-se sugerir que isto ocorra devido à crescente demanda de praticantes de atividades físicas para que os professores de educação física indiquem tais substâncias, a despeito de sua competência na área. A interação cotidiana com o público das academias favorece que esse profissional seja visto como detentor de um saber prático sobre formas rápidas de obtenção da musculosidade, o que acaba muitas vezes gerando tensões, ou seja, dilemas éticos entre os profissionais do circuito dos esportes.

A matéria "No flagra" (2010) avança em admitir que os lutadores profissionais lançam mão deste meio artificial para vencer nas competições. A classificação da substância utilizada e a identificação do atleta também são pontos importantes a partir do qual podemos ver que algo mudou: nos anos 90 as matérias não citavam nomes dos lutadores e traziam apenas caricaturas ridicularizando os usuários. Outra inovação é o fato de trazer o depoimento de um atleta renomado, declarando a disseminação do doping na luta: "metade dos lutadores de MMA usa esteróides: é difícil aguentar a pressão física e mental de se manter no topo, tudo empurra você para usar anabolizantes” (n.178, p.70, 2010).

$\mathrm{O}$ que fica desta declaração são as pressōes sofridas pelos lutadores para assumirem a liderança dos campeonatos; transparece ainda que são obrigados a ultrapassar os limites do corpo à base de doping. Na mesma reportagem, outro lutador admite a impunidade e a possibilidade de trapaça: "Como pode? Eu faço exame de doping em todas as minhas lutas e nunca fui pego (risos)" (ibidem). Isto pode sugerir a prática de limpeza do organismo (washout) ou ainda utilização de drogas difíceis de detectar no doping.

$\mathrm{Na}$ mesma linha do reconhecimento do uso, a matéria formula a questão sobre uma possível saída para o doping. A solução apontada envolveria a adoção de exames de doping em competições nacionais em modalidades como jiu-jitsu, 
muay thai e kickboxing, que normalmente não possuem fiscalização. Há uma defesa do exame de doping no período da competição e fora dela, onde a ausência de controle permitiria que os atletas ficassem "mal acostumados" à impunidade. No trecho abaixo, o depoimento de um treinador ilustra as dificuldades de controlar os ímpetos dos atletas em busca da "satisfação" promovida pelos EAA:

Comandar diversos lutadores em uma academia é trabalhoso, e é complicado controlar o que todos estão consumindo. Já me pediram para usar muitas vezes. Eu sempre indico procurar um endocrinologista, pois ele é o único que realmente saberá em primeiro lugar se o atleta pode e se tem real necessidade do uso de anabolizantes, até porque existem pessoas que realmente necessitam de tratamentos hormonais, contanto que seja determinado e acompanhado por este profissional da área (ibidem).

No entanto, na sequência da reportagem, a forma condenatória é reafirmada através da pergunta: "Quem tem culpa no cartório?”. A matéria divulga uma lista de todos os lutadores de MMA que já foram pegos no exame de doping, revelando as substâncias ingeridas por estes. A grande maioria foi detectada positiva para EAA. Por sua vez, a divulgação dos nomes desses atletas evidencia, como foi dito, uma inovação no tratamento da questão.

\section{A perspectiva dos lutadores}

Apesar de a pesquisa focalizar as matérias que traziam em seus títulos as palavras "doping" e/ou "anabolizantes", o tema apareceu em outras matérias e espaços da revista, como na coluna de cartas dos leitores e em "frases do ano" de lutadores. Por isso, também se considerou importante analisar esse material. O objetivo foi captar a perspectiva destes com relação à utilização de doping e/ou EAA, a partir dos discursos mais frequentes.

A reportagem "Um lugar ao Sol" (2008) relata a trajetória de um campeão mundial, "Pezão", desde a sua infância "simples" até o sucesso no esporte. O enfoque é dado aos desafios enfrentados pelo lutador que quase o afastaram da carreira de sucesso, dentre os quais a infância pobre, problemas de saúde e a condição financeira. Ao final da matéria, havia um box com o seguinte título: "Não preciso de anabolizante pra vencer". O comentário dava conta de que ele fora pego no exame de doping durante um campeonato mundial. O laudo da Comissão Atlética apontava a utilização de boldenona. Entretanto, o atleta afirma que "sofreu perseguição" e finaliza a entrevista com uma declaração de inocência: 
Estou me sentindo prejudicado pelos exames realizados, pois tenho a convicção de que jamais fiz uso indevido de alguma substância para essa luta [...]. Estou certo de que sou realmente um campeão de verdade, não precisando estar anabolizado para obter vitórias (n.151, p.50, 2008).

Há uma retórica da negação, embora os indícios corporais e médicos mostrem o contrário. O que a fala do lutador exemplifica é que admitir o uso de anabolizantes seria como apresentar uma fraqueza. É como se a capacidade de vencer uma luta estivesse relacionada a um atributo natural, resultado somente "da força interior", uma concepção física e moral do desempenho individual (GASTALDO, 1995; WACQUANT, 2002). A negação do uso de EAA aparece aqui como mais um reforço a um padrão de masculinidade que não admite a utilização de um recurso artificial para vencer, que se aproxima da noção de self made man (KIMMEL, 1998), um tipo de homem determinado que se faz sozinho.

Essa mesma tônica foi constatada na seção "De Olho na Web", (2010) que traz pequenas matérias cuja continuação é apresentada no site da revista. Numa destas é exibido o título: "Ramon feliz com o doping", que dava conta de que um treinador de MMA estava contente, pois seu aluno teve ótimo desempenho na luta com um adversário que havia utilizado substâncias proibidas no esporte.

Em outra entrevista, essa máxima no comentário de um renomado lutador: "Nunca usei bomba, então estou rindo à toa dessa galera que está caindo. To rindo à toa porque não tenho nenhum problema com isso" (n.135 p.46, 2007). Notase, assim, que a negação de doping é uma recorrência nos discursos focalizados. Isso pode ser visto na versão dada por um médico sobre essa estratégia: "Na medicina esportiva, a gente diz que o primeiro sintoma do doping é o cara mentir" (Reportagem "No flagra", n.178,p.70, 2010).

$\mathrm{Na}$ mesma reportagem são trazidos ainda três depoimentos, todos negando o doping por consumo de EAA. O primeiro aborda o caso de "Spartan", que alega ter ingerido um coquetel de substâncias imaginando tratar-se de suplementos comuns: "Eu ganhei suplementos importados e tomei, e tinham alguns comprimidos manipulados também". O atleta menciona a ineficácia do doping para seu caso, tendo por base a sua categoria de peso: "Eu não tenho porque ter usado isso, essa é uma droga para emagrecer e ficar 'trincado', e eu não teria porque perder peso para lutar com um cara de $120 \mathrm{~kg}$ " (ibidem). 
$\mathrm{Na}$ mesma linha de minimizar a responsabilidade individual, estão os depoimentos de dois renomados atletas do MMA que sofreram puniçôes dos órgãos institucionais.

Eu não tinha ideia de que um suplemento vendido numa loja na cidade poderia conter uma substância ilegal no estado de Nevada. Essa falta de informação está me custando caro e está acabando com a minha imagem em relação à mídia brasileira (Victor Belfort, p.70).

Eu nunca, em 14 anos de carreira, tomei nada além de suplementos naturais e proteínas naturais. Estou chocado que qualquer coisa tenha sido achada no meu organismo. Estou analisando esse assunto agora mesmo, e apelarei com a Comissão Atlética (Royce Gracie, p.72).

Essas falas sugerem o uso não intencional como uma tática amplamente utilizada no ambiente das lutas tendo em vista o estigma que carregam os atletas "sujos", isto é, dopados. Outro exemplo disso pode ser visto a seguir. Um lutador acusa um restaurante de ter oferecido gado anabolizado no cardápio:

Esse tipo de bomba é pra engordar, e é uma parada usada em animais. Tive seminários no Peru e no Chile e só comi em churrascarias, e eles utilizam muito este tipo de produto em gado e cabras por lá, e é possível que tenham usado em algum animal que eu comi (Alexandre Pequeno, ibidem).

A perspectiva dos lutadores tem por base os mesmos elementos, isto é, uma mesma postura que frequentemente culpa um agente externo, negando e condenando a utilização deste meio considerado artificial.

\section{Publicidade na Tatame: músculos e suplementos}

Nesta etapa, demos destaque para a publicidade de suplementos nutricionais. A publicidade pode ser entendida como um lugar onde se disseminam e se enfatizam determinados comportamentos, que são construídos, porém, no contexto mais amplo da vida social (FARIAS, 2003, p. 210). Essa perspectiva converge com a de Rocha (1995), segundo a qual a publicidade é um sistema de significação que conforma valores a partir dos quais se constroem práticas sociais.

Das cinco reportagens analisadas, duas apresentavam, ao final da página, um box com o anúncio de suplementos (figura 5). A publicidade sugere que o produto é um “equipamento” mais eficiente do que os utilizados na academia: “aumente sua massa muscular com o melhor equipamento do mercado" (n.36, s/n, 1998). A referência aqui era a um suplemento à base de albumina e proteinato de cálcio, posto à venda através de um número de telefone. 


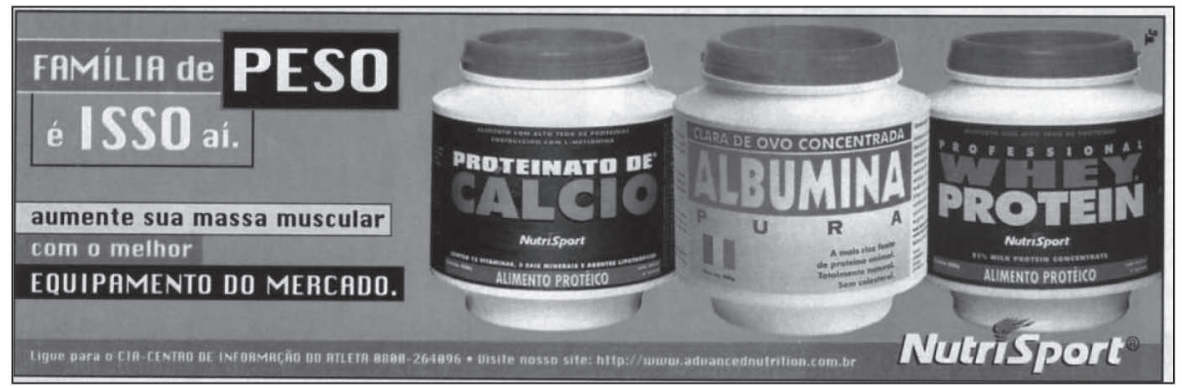

Fontes: Hormônio de Crescimento $\mathrm{GH}=\mathrm{O}$ Anabolizante da Moda. Ano 4, n.35, p.46; Substâncias Ergogênicas e Doping, ano 4, n.36, s/n.

Em todas as revistas examinadas, é frequente a veiculação de anúncios de suplementos alimentares, com destaque para aminoácidos, proteinato de cálcio, creatina, albumina, como já dito. São exibidas fotografias de homens hipermusculosos, segurando imensos potes de suplementos alimentares. Há uma clara associação entre músculos, masculinidade e superação de limites físicos. Um exemplo disso é o chamado de um anúncio: "Tome essa porrada" (n.48, s/n, 1999), segundo a figura 6 .

Figura 6- Suplementos e propaganda (II)

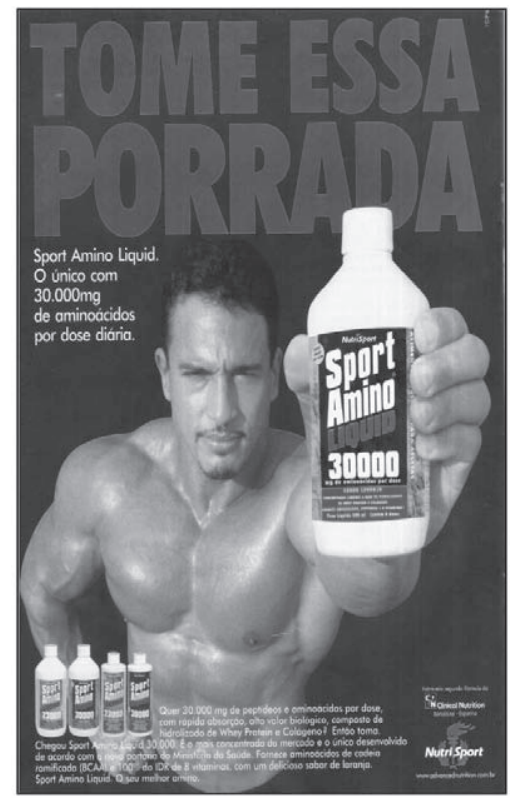

Fonte: Tome essa porrada. Ano 5, n. 49, s/p. 
Outro anúncio remete à identificação dos suplementos nutricionais como um meio natural e, portanto, saudável para o ganho muscular. "A Força Natural. A empresa X tem uma linha completa de produtos $100 \%$ naturais para você ganhar energia e massa muscular de forma rápida e segura” (n.56, s/n, 2000).

Uma propaganda promete a musculosidade rápida: "Músculos fortes e definidos! Use o mais completo suplemento alimentar em proteínas" (n.35, contracapa, 1998) (figura 7). Há uma recomendação explícita de como obter a massa desejada por quem precise de vitaminas e nutrientes vitais para um melhor desempenho, corpo forte e músculos bem definidos. O produto é apresentado como um poderoso suplemento que contém mais proteínas do que qualquer outro, além do suave sabor de ice cream. $\mathrm{O}$ anúncio termina convocando o leitor a experimentar a substância comercializada por um famoso culturista profissional, com mais de cem quilos de músculos.

Figura 7- Suplementos e propaganda (III)

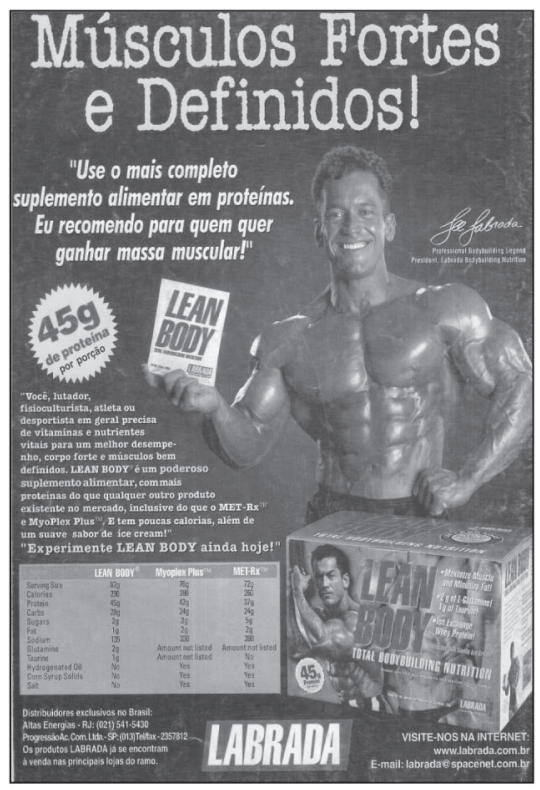

Fonte: Músculos Fortes e Definidos! Ano 4, n.35, contracapa

É possível imaginar uma articulação entre o discurso condenatório sobre os anabolizantes e a propaganda de suplementos. É como se o anúncio desviasse a atenção das "bombas" para os suplementos, tal como uma medida 
compensatória, uma “suplementação". Pode-se pensar também que o anúncio de

substâncias relacionadas ao aumento da musculosidade e do rendimento precise ser veiculado, pois integra um espaço comercial pago pelo anunciante, cobrindo os custos da revista, sustentando, portanto, sua publicação. A clivagem executada entre não-natural (anabolizantes) e natural (suplementos) é reforçada por outra, entre substâncias que precisam do aval do personagem médico e outras que são escolhidas pelo freguês e "prescritas” ou sugeridas pela própria revista. Evidência disto é a condenação do "mercado negro" de anabolizantes, representado por redes sociais e profissionais de qualificação desconhecida, de um lado, e de anúncios que incentivam a compra de suplementos através justamente de sites da Internet e pedidos por telefone.

\section{Considerações finais}

A reflexão proposta visou ampliar o conhecimento sobre as concepções e experiências coletivas ligadas à construção social da masculinidade, a partir da análise de uma revista especializada em artes marciais, cuja abordagem sobre a musculosidade é ambígua. Assim, ao mesmo tempo em que há um ponto de vista condenatório ao uso de EAA e doping para a produção de músculos, valoriza-se o uso de suplementos para o mesmo fim, por meio de propagandas e imagens que vinculam a musculosidade à superioridade masculina.

Há, portanto, a disseminação de valores ligados à hipermasculinidade. Esse padrão de masculinidade viril é cultivado em várias modalidades esportivas, mas no ambiente das artes marciais encontra espaço privilegiado, dada sua estreita relação com o processo de construção e manutenção de um ethos guerreiro isto é, de um código de conduta expresso pela disposição permanente para o confronto, visando a derrota do oponente.

Esta reflexão foi um exercício no sentido de aproximar o olhar dos discursos e das imagens que permeiam o universo das lutas marciais, uma esfera homossocial (espaço reservado para homens) na qual o "feminino" é equacionado à fraqueza e, portanto, desvalorizado. Nesse sentido, a Tatame pode ser vista como um território hipermasculino, cuja configuração encontra-se informada por um ethos ligado à virilidade. Ao enfatizar atributos masculinos da fisicalidade, da competição e valentia em suas matérias, a revista contribui para reforçar a ideia de uma masculinidade hegemônica. 
É oportuno desenvolver trabalhos que focalizam o uso de EAA e a atração que eles exercem sobre homens jovens, dada a possibilidade de construção de um estilo de masculinidade cujos liames estruturantes são a força e a agressividade, marcas corporais que conferem distinção social. Espera-se contribuir para uma reflexão sobre o uso de EAA e seus impactos para a saúde coletiva, em geral, e a masculina, em particular. ${ }^{5}$

\section{Referências}

BELELI, I. Corpo e identidade na propaganda. Rev. Estudos Feministas, Florianópolis, v. 15, n. 1, p. 193-215, 2007.

BOURDIEU, P. Os usos sociais da ciência. Por uma sociologia clínica do campo científico. São Paulo: Unesp, 2004.

CECCHETTO, F.R. A sina de ser forte. Corpo, sexualidade e saúde entre lutadores de jiujítsu no Rio de Janeiro. In:HEILBORN, Maria Luiza et al. (Org.). Sexualidade, reprodução e saúde. Rio de Janeiro: FGV, 2009. p. 509-534.

. Violência e estilos de masculinidade. Rio de Janeiro: FGV, 2004.

COURTINE, J.J. Os stakhanovistas do narcisismo: body building e puritanismo ostentatório na cultura americana do corpo. In: SANT'ANNA, D. (Org.). Políticas do corpo. São Paulo: Estação Liberdade,1995.

DOMINGUEZ, B. Quebra-cabeça. Em debate povoado de questôes, escolher as peças para se montar uma política equilibrada com foco na Saúde é desafio. Revista Radis, Rio de Janeiro, p. 13-18, jan 2011.

ELIAS, N. O Processo Civilizador. V.1: Uma História dos Costumes. Rio de Janeiro: Jorge Zahar, 1994.

FARIAS, P. Belezas negras à vista: a presença negra na publicidade brasileira dos anos 70 . In: FARIAS, P.; TRAVANCAS, I. (Org.). Antropologia e comunicação. Rio de Janeiro: Garamond, 2003. p. 209-225.

Festa, nação, etnia, personalidade: notícias da Abolição. In: MAGGIE, Y.;

CONTINS, M. (Org.). Quase catálogo 6: Visões da Abolição. Rio de Janeiro: MIS/ CIECUFRJ, 1997. p. 134-160.

GASTALDO, E.L. Kickboxers: esportes de combate e identidade masculina. 1995. Dissertação (Mestrado em Antropologia Social) - Instituto de Filosofia e Ciências Humanas, Universidade Federal do Rio Grande do Sul, Porto Alegre, 1995.

GEERTZ, C. A interpretação das culturas. Rio de Janeiro: Guanabara, 1989.323p.

HANDELSMAN, D.J. Testosterone: use, misuse and abuse. Medical Journal of Australia, v. 185 , n. 8, p. 436-439, 2006. 
IRIART, J.A.B.; ANDRADE, T.M. Musculação, uso de esteroides anabolizantes e percepção de risco entre jovens fisiculturistas de um bairro popular de Salvador, Bahia, Brasil. Cad. Saúde Pública. Rio de Janeiro, v.18, n.5, set-out.2002.

KAYSER, B.; MAURON, A.; MIAH, A. Current anti-doping policy: a critical appraisal. BMC Medical Etnics 2007. 8:2. Disponível <HTTP://biomedcentral.com/1472-6939/8/2>. Acesso em: 25 fev 2011.

KIMMEL, M.S. A produção simultânea de masculinidades hegemônicas e subalternas. Horizontes Antropológicos: corpo, saúde e doença, Porto Alegre, ano 4, n. 9, 103-117, out. 1998. KLEIN, A.M. Little big men: bodybuilding subculture and gender construction. Albany: State University of New York Press, 1993. 326p.

LE BRETON, D. Adeus ao corpo: antropologia e sociedade. Campinas: Papirus, 2003.

MESSNER, M.A.B., Organized sports, and the construction of masculinities. In: KIMMEL. M.; MESSNER, M. (Org.). Men's Lives. Boston, 2001.

MINAYO, M.C. O desafio do conhecimento: pesquisa qualitativa em saúde. São Paulo: Hucitec, 2008.

POPE JR, H.G. et al. Evolving ideals of male body image as seen through action toys. Int. J. Eat Disord., v. 26, p. 65-72, 1999.

REVISTA TATAME. Anabolizantes: a sua saúde em perigo. Ano 5, n.48, p.34-36, 1999. Doping: Você sabe o que está tomando?Ano 6, n. 56, s/n, 2000. . Entrevista. Novembro de 2007, p.46, 2007. . Hormônio de Crescimento GH= O Anabolizante da Moda. Ano 4, n.35, p.46, 1998. . No flagra. n. 178, dezembro de 2010. P.68-72, 2010. . Substâncias Ergogênicas e Doping. Ano 4, n.36, s/n, 1998. . Tome essa porrada. Ano 5, n. 49, s/p, 1999. . Um lugar ao sol. n.151, p.46-50, 2008.

ROCHA, E. Magia e capitalismo. São Paulo: Brasiliense, 1995

SABINO, C. Anabolizantes: drogas de Apolo. In: GOLDENBERG, M. et al (Org.). Nu \& Vestido: dez antropólogos revelam a cultura do corpo carioca. Rio de Janeiro: Record, 2002. SILVA, P.R.P. et. al. Prevalência do uso de agentes anabólicos em praticantes de musculação de Porto Alegre. Revista da ABEM, v. 51, p. 104-110, 2007.

SILVA, P.R.P.; DANIELSKI, R.; CZEPIELEWSKI, M.A. Esteroides anabolizantes no esporte. Rev.Bras Med Esporte, v. 8, n. 6, Nov-dez, 2002.

THIBLIN, I.; PÄRKLO, T. Anabolic androgenic steroids and violence. Acta Psychiatr Scand, v. 106, supl. 412, p. 125-128, 2002. 
WACQUANT, L. Corpo e alma: notas etnográficas de um aprendiz de boxe. Rio de Janeiro: Relume Dumará, 2002. 293p.

ZALUAR, A. Integração perversa: pobreza e tráfico de drogas. Rio de Janeiro: FGV, 2004. 438p.

\section{Notas}

${ }^{1}$ Esses autores mencionam o advento dos esteroides anabolizantes e de outras drogas voltadas para a modificação corporal como explicação para o incremento desse ideal nos últimos 40 anos, permitindo a transformação muscular que não seria obtida por meio naturais.

${ }^{2}$ Dentre os efeitos adversos mencionados, estão disfunções em órgãos vitais como coração e fígado, alteraçóes psíquicas e comportamentais, envolvendo, em alguns casos, episódios de agressividade, violência interpessoal, vandalismo, homicídios e suicídios ( PARKLO, 2002).

${ }^{3}$ No site da revista consta que aproximadamente 70.000 pessoas leem a revista todos os meses, sendo $76 \%$ homens e $24 \%$ mulheres. Destes, $70 \%$ se situam na faixa de idade dos 15 aos 35 anos. Com relação à escolaridade, $54 \%$ possuem o segundo grau, enquanto que $33 \%$ possuem ensino superior e $13 \%$ possuem o primeiro grau. A tiragem média é de 22.000 exemplares, com distribuição nacional (http://www.tatame.com.br).

${ }^{4} \mathrm{O}$ incidente que ocorreu na Olimpíada de Sidney ilustra bem um exemplo de suplementação à base de creatina contaminada por anabolizantes, inadvertidamente utilizada por atletas de alto rendimento (SILVA et al., 2002).

${ }^{5} \mathrm{~F}$. Cecchetto foi responsável pela pesquisa original, participando de todas as etapas do estudo, desde a revisão da literatura até a redação final. P. Farias foi responsável pela metodologia para a análise do material jornalístico e participou da interpretação desse material e da redação do artigo. P.R.da Silva participou da análise do material e revisão do texto nas áreas biomédica e esportiva. J. S.Corrêa trabalhou na coleta, seleção e sistematização do material analisado, além da interpretação dos dados e redação do texto. 


\section{Where the weak have no place: discourses on steroids, body and masculinities in a specialized magazine}

This study aims to analyze the materials on anabolic androgenic steroids (AAS) and doping, published in a magazine specializing in martial arts, Tatame, between the years 1996 and 2010. We used qualitative methodology, from the benchmark provided by the Social Sciences and its interfaces with Public Health. The analysis and discussion of the discourses about the use of AAS and doping were organized into four phases: first, there was a comprehensive reading of journalistic material; in the second, the subjects were examined, focusing on titles, subtitles and content. In the third, it was the surroundings of boxes, covers, back covers and magazine advertising space. The fourth stage favored the perspective of fighters on the use of EAA and / or doping, conveyed both in matters where these uses are the central focus, as in stories in which they are not the main theme. The results indicate a mismatch between the content conveyed in the press, which, on one hand, condemns the use of AAS and doping, and the other, discloses a series of stimuli for the development of muscularity. Thus, the contents eventually support the idea of close association between muscularity and a kind of traditional masculinity positivization anchored in the strength and invincibility.

> Key words: doping; anabolic steroids; warrior ethos; masculinity; media. 